\title{
Heart rate variability in critically ill subjects
}

\author{
Meldijana Omerbegović* \\ University Clinical Centre Sarajevo, Sarajevo, Bosnia and Herzegovina
}

Heart rate variability, a phenomenon of variations of the length of consecutive heat cycles reflects the autonomic modulation of the heart function. Parameters of monitoring the heart rate variability are suggested to be important in the assessment of autonomic neuropathy that may complicate several pathological conditions, with established clinical importance in predicting morbidity and mortality in patients with coronary syndrome and in patients with diabetes mellitus. The complexity of the critical illness of the subjects in the intensive care unit demands complex pharmacological

\section{Received: $20^{\text {th }}$ Apr 2014}

*Address for correspondence: Klinički centar Univerziteta u Sarajevu, Bolnička 25 , 710000 Sarajevo, Bosnia and Herzegovina.

Phone: +387-33-297-000

E-mail: meldi@bih.net.ba and procedural therapeutic interventions and measures, which all have a significant impact on the parameters of heart rate variability. Such complex interactions limit the possibility to reach conclusions on a potential degree of the influences of the deteriorated organ function and the influence of the therapeutic interventions. Despite difficulties and limitations of interpretation of the variations and depression of the heart rate variability parameters, research in this field has been continuing.

In this paper, different parameters of short-term heart rate variability monitored in 25 consecutive patients who were admitted to an adult intensive care medicine unit for different conditions of critical illness are presented.

KEYWORDS: heart rate variability, critical illness, autonomic nervous modulation.

CITATION: Cardiol Croat. 2014;9(5-6):208.

\section{Literature}

1. Task Force of The European Society of Cardiolgy and the North American Society of Pacing and Electrophysiology. Heart rate variability: standards of measurement, physiogical interpretation and clinical use. Circulation. 1996;93:1043-65.

2. Goldstein B, Fiser D, Kelly MM, Mickelsen D, Ruttiman U, Pollack M: Decomplexification in critical illness and injury:Relationship between heart rate variability, severity of illness, and outcome. Crit Care Med.1998;26(2):352-7.

3. Haji-Michael PG, Vincent JL, Degante JP, van de Borne P. Power spectral analysis of cardiovascular variability in critically ill neurosurgical patients. Crit Care Med. 2000;28:257883. 